Original Research Paper

\title{
Ameliorative Impacts of Tribulus terrestris Against Ivermectin-Induced Hepato-Renal Toxicity in Rabbit: Pharmacological and Histopathological Study
}

\author{
${ }^{1}$ Sally I. Ismaiel, ${ }^{2}$ Sameh M. Farouk, ${ }^{1}$ Raafat A. El-Ramady and ${ }^{3}$ Waleed F. Khalil \\ ${ }^{1}$ Animal Health Research Institute-El-Mansoura, Egypt \\ ${ }^{2}$ Department of Cytology and Histology, Faculty of Veterinary medicine, Suez Canal University, Ismailia, 41522, Egypt \\ ${ }^{3}$ Department of Pharmacology, Faculty of Veterinary medicine, Suez Canal University, Ismailia, 41522, Egypt
}

Article history

Received: 29-07-2016

Revised: 07-01-2017

Accepted: 11-01-2017

Corresponding Author: Waleed Fathy Khalil

Department of Pharmacology,

Faculty of Veterinary medicine,

Suez Canal University,

Ismailia, 41522, Egypt

Email: wk@vet.suez.edu.eg

\begin{abstract}
The current work aimed to investigate the protective effects of Tribulus terrestris extracts against ivermectin-induced hepatic and renal toxicity in male rabbit. Selenium plus vitamin E was used as a comparative standard drug to evaluate the efficacy of Tribulus terrestris extract on some hematological parameters, kidney and liver enzymes as well as associated histopathological changes. This work was carried out on thirty male New Zealand rabbits for two successive months. Animals were divided into five groups of six rabbits each. The 1st group was designated as the negative control; the 2nd group was subcutaneously injected with ivermectin (IVM) $(200 \mu \mathrm{g} / \mathrm{kg} / \mathrm{month})$. The 3rd group was treated daily with selenium plus vitamin $\mathrm{E}(\mathrm{Se}+$ vit $\mathrm{E})$ after IVM injection. The 4 th and 5 th groups were treated with Tribulus terrestris Ethanol Extract (TTE) and Tribulus Terrestris Ethyl Acetate extract (TTEA) respectively at a dose of $5 \mathrm{mg} / \mathrm{kg}$ /day after IVM injection. Hematological results showed significant $(\mathrm{P}<0.05)$ increases in RBCs, hemoglobin and hematocrit percentage after both TTE and TTEA extracts treatment compared to IVM and $\mathrm{Se}+$ vit $\mathrm{E}$ groups. There was a significant decrease in AST activity in TTE and Se + vit E treated groups $(17.17 \pm 0.95$ and $16.50 \pm 0.76 \mathrm{U} / \mathrm{L})$ and non-significant decreased activity in TTEA group $(18.83 \pm 0.6 \mathrm{U} / \mathrm{L})$ compared with IVM injected group $(21.5 \pm 1.31 \mathrm{U} / \mathrm{L})$. Moreover, there were non-significant $(\mathrm{P}<0.05)$ changes in both serum creatinine and urea concentrations in IVM, TTE, TTEA and Se + vit E treated groups. Regarding to histo-architectural changes, TTE treated group revealed mild degenerative changes in the renal parenchyma with congested blood vessels, meanwhile, the TTEA treated group revealed few degenerative changes in hepatocytes. This study concluded that, Tribulus terrestris extracts could be used as an effective treatment to ameliorate the ivermectin-induced renal and hepatic toxicity in rabbits.
\end{abstract}

Keywords: Tribulus terrestris, Ivermectin, Selenium, Vitamin E, HepatoRenal Toxicity

\section{Introduction}

Avermectins, have been isolated from fermented products of Streptomyces Avermititis, are a family of insecticidal agents with acricide and anthelmintic activities. Ivermectin (IVM), a derivative of avermectins, exhibits a broad spectrum of activity against gastrointestinal and lung nematodes as well as against ectoparasites of clinical relevance in domestic animals (Suarez et al., 2013). It was reported that, IVM induces deleterious effects in kidney and hepatic functions, oxidative stress as well as weight loss (El-Far, 2013). In rats, liver obtained at $24 \mathrm{~h}$ post last injection of IVM revealed congestion of hepatic blood vessels and blood sinusoids in association with vacuolated cytoplasm of hepatocytes. Moreover, congestion of the renal blood vessels and intertubular capillaries, hypercellularity glomerular tufts with proliferation of the capillaries lining endothelial cells were also noticed (Rabab et al., 2015). 
Among antioxidants, selenium is an essential nutritional element for all biological systems that has a component of major antioxidant enzymes and selenoproteins (glutathione peroxidase, thioredoxin reductase). It inhibits membrane lipid peroxidations (Yuan and Tang, 1999; Ben Amara et al., 2011). Glutathione peroxidase is responsible for detoxification in the body by reducing peroxide free radicals that include lipid peroxide formation in cell membranes (Stranges et al., 2010). Vitamin $\mathrm{E}$ is one of the most extensively studied fat soluble vitamins, its antioxidant and hepato-renal protective effects were subjects of many research works (Al-Othman et al., 2011; Abogresha et al., 2016).

Tribulus terrestris contains biologically active substances such as steroids, saponins, flavonoids, alkaloids, unsaturated fatty acids, vitamins, tannins, resins, nitrate, potassium, aspartic acid, glutamic acid, oils, calcium and glycoconjugates (Karimi et al., 2012; Sangeeta et al., 1994). Glycoconjugates are a class of complex molecules those are widely distributed in the plant kingdom and in some marine organisms. This class of compounds has a wide range of biological activities as anti-inflammatory, antimicrobial, antifungal, anticancer and other benefits. Among these compounds, total phenolics, total flavonoids, triterpenoid and saponins have long been known as components of widely used herbal drugs and preparations (Abdou et al., 2015).

Hence, the main goal of the present work was to study the possible protective effect of Tribulus terrestris extracts against IVM-induced hepato-renal toxicity in comparison to selenium plus vitamin $\mathrm{E}$ as a standard antioxidant drug. For that purpose, the hematological parameters, liver and kidney biomarker enzymes as well as hepatic and renal histopathological features were examined.

\section{Materials and Methods}

\section{Drugs, Chemicals and Kits}

Ivermectin (paramectin ${ }^{\circledR}$ ) was purchased from Pharma Swede Company (Cairo, Egypt) in the form of a liquid solution containing ivermectin at $1 \%$. Selenium plus vitamin E (Alfa-S20®) was purchased from German Company, 10th Ramadan, Egypt in the form of a liquid solution containing sodium selenite plus vitamin E (0.8 $\mathrm{mg}$ and $200 \mathrm{mg} \mathrm{mL}^{-1}$, respectively). Tribulus terrestris fruits were obtained from Egypt (natural habitats) and undergo an extraction procedure according to Lakshmi et al. (2012). Briefly, $1 \mathrm{Kg}$ of the pulverized dried plant was extensively extracted with $2 \mathrm{~L}$ of ethyl acetate in separating funnel. The remaining plant part was subjected to further extraction using $2 \mathrm{~L}$ of $70 \%$ ethanol. Both Tribulus Terrestris Ethyl Acetate (TTEA) and Tribulus Terrestris Ethanol (TTE) extracts were evaporated to dryness under vacuum using a rotatory evaporator at $25^{\circ} \mathrm{C}$. The obtained crusts (69.52 and 11.12 gm for ethyl acetate and ethanol solvents, respectively) were reconstituted in solvent vehicle (glycerol: Dimethyl sulphoxide, 95:5, v:v) to be suitable for oral administration.

Serum Aspartate Aminotransferase (AST) and Alanine Amino Transferase (ALT) were determined using readymade kits from ELITech Clinical Systems AST and ALT reagents, France. Serum Alkaline Phosphatase (ALP) was determined using ready-made kits from SPINREACT ALP reagent, Spain. Serum urea was determined using readymade kits from Diamond urea reagent, Egypt. Serum creatinine was determined using ready-made kits from BioMed Diagnostics creatinine, Egypt.

\section{Animals and Experimental Design}

In this study, a total of thirty apparently healthy male New Zealand rabbits weighing $3.4 \pm 0.3 \mathrm{~kg}$ and aged 22 weeks were used. Rabbits were individually housed in galvanized wire cages under hygienic conditions. Concentrate pelleted feed and water were provided ad libitum throughout the experiment.

After 14 days of acclimatization, the studied animals were randomly divided into five groups of six rabbits per each. Group I (negative control) was received solvent vehicle, group II (positive control) was injected subcutaneously with ivermectin at a dose of $200 \mu \mathrm{g} / \mathrm{kg}$ body weight/month for two successive months, group III was injected with ivermectin as in group II while being administered with selenium plus vit $\mathrm{E}(\mathrm{Se}+$ vit $\mathrm{E})$ at a daily dose of $1 \mathrm{ml} / \mathrm{L}$ drinking water (Biswas et al., 2011), group IV was injected with ivermectin as in group II and treated at the same time was with TTE extract at a dose of $5 \mathrm{mg} /$ day $/ \mathrm{kg}$ BW and group $\mathrm{V}$ which has received ivermectin such as group II while being treated with TTEA extract at a dose of $5 \mathrm{mg} / \mathrm{day} / \mathrm{kg} \mathrm{BW}$ (Kostova and Dinchev, 2005; Gauthaman and Adaikan, 2008). The experimental design and animal handling were done in accordance with the guidelines of the National Institutes of Health (NIH) guidelines and were approved by the Egyptian local committee at Suez Canal University, Faculty of Veterinary Medicine.

At the end of the experiment, blood samples were collected from ear veins of the studied bucks. Blood samples, collected by syringe containing one drop of EDTA as an anticoagulant, were used to determine the hematological parameters. Meanwhile, other samples were collected without anticoagulant and then centrifuged (15 min, 3,000 rpm) and serum was removed and stored frozen at $-20^{\circ} \mathrm{C}$ until radioimmunoassay.

\section{Blood Parameters}

The Red Blood Cells (RBCs, $\times 10^{6} / \mu \mathrm{L}$ ) count count was determined by using hemocytometer according to Perkins (2009), while the hemoglobin (Hb, g/dL) was evaluated colorimetrically according to Van Kampen and Zillstra (1983). Hematocrit percentage (Ht \%) was measured by capillary tubes, the opposite end of the tubes was sealed and then centrifuged for $10 \mathrm{~min}$ at 
3,000 rpm according to Bauer (1970). The White Blood Cells (WBCs, $\times 10^{3} / \mu \mathrm{L}$ ) were counted by using hemocytometer according to Ewuola and Egbunike (2008).

\section{Serum Liver and Kidney Biochemical Parameters}

Collected sera were subjected to biochemical analysis of AST, ALT, ALP, urea and creatinine. Each parameter was estimated according to the instructions of its kit. AST and ALT were quantitatively estimated according to the method described by Reitman and Frankel (1957). Creatinine and urea were determined according to the methods of Young et al. (1975; Yatzidis et al., 1964), respectively. These parameters were spectrophotometrically assayed by using semi-automated spectrophotometer.

\section{Light Microscopic Examination}

At the end of the experiment, all bucks were slaughtered and small pieces of livers and kidneys were excised for histopathological examination. The obtained specimens were kept in $10 \%$ neutral buffered formalin, then subjected to routinely histological procedures, dehydrated in ascending grades of alcohol, cleared in xylene, embedded in soft paraffin at $60^{\circ} \mathrm{C}$ and then blocked in hard paraffin. The embedded paraffin sections were cut at $5 \mu \mathrm{m}$ thickness and stained with hematoxylin and eosin (Bancroft and Gamble, 2008). The slides were examined under a research optical photomicroscope fitted with an Olympus DP25 digital camera, department of Cytology and Histology, Faculty of Veterinary Medicine, Suez Canal University, Egypt.

\section{Statistics}

Statistical analysis was done using Statistical Package of Social Sciences (SPSS), version 17, (Inc., Chicago, IL, USA) computer software. Data were expressed as mean \pm SE. Differences between groups were analyzed using one-way ANOVA, $\mathrm{P}<0.05$ was considered as statistically significant. Treatment means indicating significant differences $(\mathrm{P}<0.05)$ were tested using Duncan's multiple range test (Duncan, 1955).

\section{Results}

\section{Blood Parameters}

The current investigation showed significant $(\mathrm{P}<0.05)$ increases in the RBCs count after both TTE and TTEA extract treatments $(5.43 \pm 0.28$ and $\left.5.36 \pm 0.31 \times 10^{6} / \mu \mathrm{L}\right)$ compare to IVM and $\mathrm{Se}+$ vit $\mathrm{E}$ groups $\left(4.07 \pm 0.52\right.$ and $3.93 \pm 0.31 \times 10^{6} / \mu \mathrm{L}$, respectively). Comparable results were observed regarding to $\mathrm{Hb}$ concentrations and $\mathrm{Ht}$ percentage. Significant $(\mathrm{P}<0.05)$ increases in $\mathrm{Hb}$ concentrations were recorded in TTE and TTEA extracts treated groups (11.34 \pm 0.48 and $11.98 \pm 0.56 \mathrm{~g} / \mathrm{dL}$, respectively) compared to IVM and $\mathrm{Se}+$ vit $\mathrm{E}$ groups $(8.94 \pm 1.04$ and $8.48 \pm 0.48 \mathrm{~g} / \mathrm{dL}$, respectively). Similarly, significant $(\mathrm{P}<0.05)$ increased $\mathrm{Ht}$ percentages were recorded in TTE and TTEA groups $(36.48 \pm 1.87$ and $37.28 \pm 1.73 \%)$ compared to IVM and $\mathrm{Se}+$ vit E groups $(30.16 \pm 1.97$ and $25.26 \pm 0.77 \%$, respectively) as shown in Table 1 .

Regarding to WBCs count, the results in Table 1 show significant $(\mathrm{P}<0.05)$ decrease in $\mathrm{WBCs}$ count in TTE, TTEA and $\mathrm{Se}+$ vit E treated groups $(8.1 \pm 0.28$, $8.32 \pm 0.65$ and $\left.4.84 \pm 0.65 \times 10^{3} / \mu \mathrm{L}\right)$ compared to control group $\left(10.26 \pm 0.06 \times 10^{3} / \mu \mathrm{L}\right)$.

\section{Serum Liver and Kidney Biochemical Parameters}

Data presented in Table 2 show a significant $(\mathrm{P}<0.05)$ decreases in AST activity in TTE extract and Se + vit E treated groups $(17.17 \pm 0.95$ and $16.50 \pm 0.76 \mathrm{U} / \mathrm{L})$ and non-significantly decreased activity in TTEA treated group $(18.83 \pm 0.6 \mathrm{U} / \mathrm{L})$ compared to IVM injected group $(21.5 \pm 1.31 \mathrm{U} / \mathrm{L})$.

On the other hand, there were no changes in both ALT and ALP after IVM, TTE, TTEA or Se + vit E administrations.

Regarding to the effects of Tribulus terrestris extracts on kidney enzymes, data presented in Table 3 show insignificant $(\mathrm{P}<0.05)$ changes in both creatinine and urea serum concentrations after IVM, TTE, TTEA or $\mathrm{Se}+$ vit E. Although, IVM slightly elevated serum creatinine and urea and TTE, TTEA and Se + vit E reduced this elevation; none of these changes were significant.

\section{Histopathological Examination}

In all five treated-groups, hepatic and renal specimens were processed further for histopathologic analysis. Architectural changes were successively recorded in the selected organs of experimental rabbits.

Table 1. Effects of IVM, Se + vit E and Tribulus terrestris extracts on some hematological parameters

\begin{tabular}{llllll}
\hline Parameters & Negative control & IVM & TTE extract & TTEA extract & Se + vit E \\
\hline RBCs $\left(10^{6} / \mu \mathrm{L}\right)$ & $5.47 \pm 0.19^{\mathrm{a}}$ & $4.07 \pm 0.52^{\mathrm{b}}$ & $5.36 \pm 0.31^{\mathrm{a}}$ & $5.43 \pm 0.28^{\mathrm{a}}$ & $3.93 \pm 0.31^{\mathrm{b}}$ \\
$\mathrm{WBCs}\left(10^{3} / \mu \mathrm{L}\right)$ & $10.26 \pm 0.62^{\mathrm{a}}$ & $8.92 \pm 0.56 \mathrm{a}^{\mathrm{b}}$ & $8.32 \pm 0.65^{\mathrm{b}}$ & $8.10 \pm 0.28^{\mathrm{b}}$ & $4.84 \pm 0.65^{\mathrm{c}}$ \\
$\mathrm{Hb}(\mathrm{g} / \mathrm{dL})$ & $11.3 \pm 0.34^{\mathrm{a}}$ & $8.94 \pm 1.04^{\mathrm{b}}$ & $11.34 \pm 0.48^{\mathrm{a}}$ & $11.98 \pm 0.56^{\mathrm{a}}$ & $8.48 \pm 0.48^{\mathrm{b}}$ \\
$\mathrm{Ht} \%$ & $36.28 \pm 1.1^{\mathrm{a}}$ & $30.16 \pm 1.97^{\mathrm{b}}$ & $36.48 \pm 1.87^{\mathrm{a}}$ & $37.28 \pm 1.73^{\mathrm{a}}$ & $25.26 \pm 0.77^{\mathrm{c}}$ \\
\hline
\end{tabular}

Values are means \pm standard error (Mean \pm SE). Different latter in one row indicates significant difference at $\mathrm{P}<0.05$. IVM $=$ ivermectin, TTE extract $=$ Tribulus terrestris ethanol extract, TTE extract $=$ Tribulus terrestris ethyl acetate extract, $\mathrm{Se}+\mathrm{vit} \mathrm{E}=$ Selenium plus vitamin E, RBCs $=$ red blood cells, WBCs $=$ white blood cells, $\mathrm{Hb}=$ hemoglobin and $\mathrm{Ht} \%=$ hematocrit percentage. 
Table 2. Effects of IVM, Se + vit E and Tribulus terrestris extracts on liver biomarker enzymes

\begin{tabular}{llllll}
\hline Parameters & Negative control & IVM & TTE extract & TTEA extract & Se + vit E \\
\hline AST (U/L) & $16.5 \pm 0.76^{\mathrm{b}}$ & $18.8 \pm 0.6^{\mathrm{ab}}$ & $17.2 \pm 0.95^{\mathrm{b}}$ & $21.5 \pm 1.31^{\mathrm{a}}$ & $16.0 \pm 0.93^{\mathrm{b}}$ \\
ALT (U/L) & $44.2 \pm 0.91^{\mathrm{a}}$ & $46.7 \pm 2.04^{\mathrm{a}}$ & $45.7 \pm 2.51^{\mathrm{a}}$ & $49.0 \pm 2.48^{\mathrm{a}}$ & $43.8 \pm 2.44^{\mathrm{a}}$ \\
ALP & $54.7 \pm 2.95^{\mathrm{a}}$ & $65.7 \pm 5.21^{\mathrm{a}}$ & $59.3 \pm 4.02^{\mathrm{a}}$ & $66.2 \pm 5.03^{\mathrm{a}}$ & $53.8 \pm 4.19^{\mathrm{a}}$ \\
\hline
\end{tabular}

Values are means \pm standard error (Mean \pm SE). Different latter in one row indicates significant difference at $\mathrm{P}<0.05$. IVM $=\mathrm{ivermectin}$, TTE extract $=$ Tribulus terrestris ethanol extract, TTE extract $=$ Tribulus terrestris ethyl acetate extract, $\mathrm{Se}+$ vit E $=$ Selenium plus vitamin $\mathrm{E}, \mathrm{AST}=$ Serum aspartate aminotransferase, $\mathrm{ALT}=$ alanine amino transferase and ALP $=$ alkaline phosphatase.

Table 3. Effects of IVM, Se + vit E and Tribulus terrestris extracts on kidney biomarker enzymes

\begin{tabular}{|c|c|c|c|c|c|}
\hline Parameters & Negative control & IVM & TTE extract & TTEA extract & $\mathrm{Se}+$ vit $\mathrm{E}$ \\
\hline Creatinine $(\mathrm{mg} / \mathrm{dL})$ & $1.09 \pm 0.05^{\mathrm{a}}$ & $1.19 \pm 0.06^{\mathrm{a}}$ & $1.14 \pm 0.04^{\mathrm{a}}$ & $1.21 \pm 0.07^{\mathrm{a}}$ & $1.03 \pm 0.06^{\mathrm{a}}$ \\
\hline $\operatorname{Urea}(\mathrm{mg} / \mathrm{dL})$ & $46.0 \pm 1.23^{\mathrm{a}}$ & $47.7 \pm 2.4^{\mathrm{a}}$ & $50.7 \pm 2.94^{\mathrm{a}}$ & $51.2 \pm 2.46^{\mathrm{a}}$ & $44.1 \pm 3.1^{\mathrm{a}}$ \\
\hline
\end{tabular}

Values are means \pm standard error (Mean $\pm \mathrm{SE}$ ). Different latter in one row indicates significant difference at $\mathrm{P}<0.05$. IVM $=$ ivermectin, TTE extract $=$ Tribulus terrestris ethanol extract, TTE extract $=$ Tribulus terrestris ethyl acetate extract and $\mathrm{Se}+$ vit $\mathrm{E}=$ Selenium plus vitamin E.
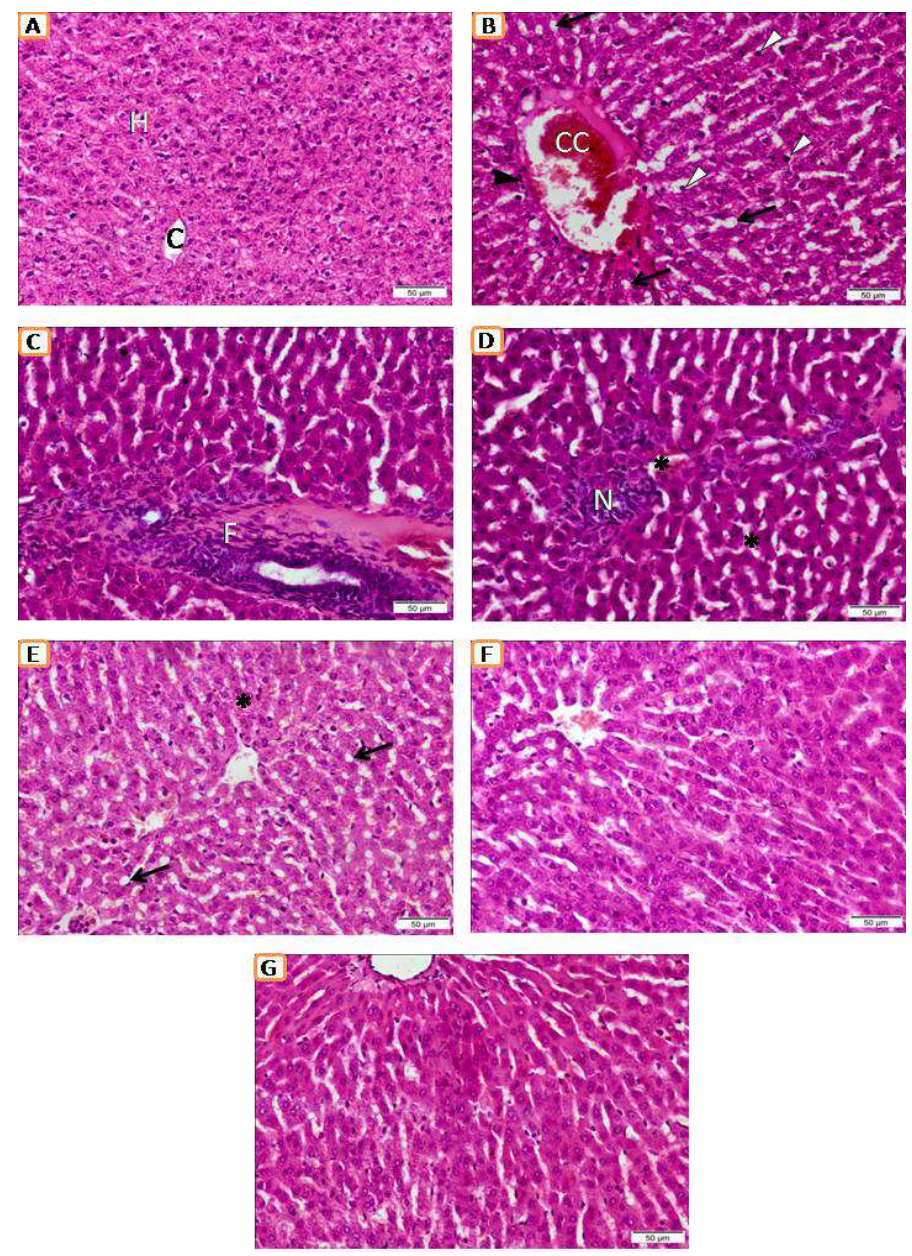

Fig. 1. Photomicrographs of rabbit liver: A. Control group showing normal hepatic architecture with normally arranged hepatocytes (H) radiated from central vein $(\mathrm{C}) ; \mathrm{B}, \mathrm{C}$ and D. IVM-treated group showing vacuolar degeneration in some pyknotic hepatocytes (arrows), kuppfer cell hyperplasia (white arrowheads), lymphocytic infiltration around the central vein (black arrowheads), evidence of marked congestion and dilatation of central vein (CC) and sinusoids (asterisk), fibrous connective proliferation around the portal area (F), marked diffuse necrobiotic changes of hepatic tissue (N); E. TTE animals' liver showed congested and dilated sinusoids (asterisk) vaccular degeneration of hepatocytes (arrows); F. TTEA group revealed few degenerative changes of hepatocytes, as well as congestion and dilatation of central vein and sinusoids; G. Se + vit E treated animals' liver showed near normal hepatic architecture with very mild degenerative changes of some hepatocytes, others showed regeneration in the rest of the cells. H\&E stain 

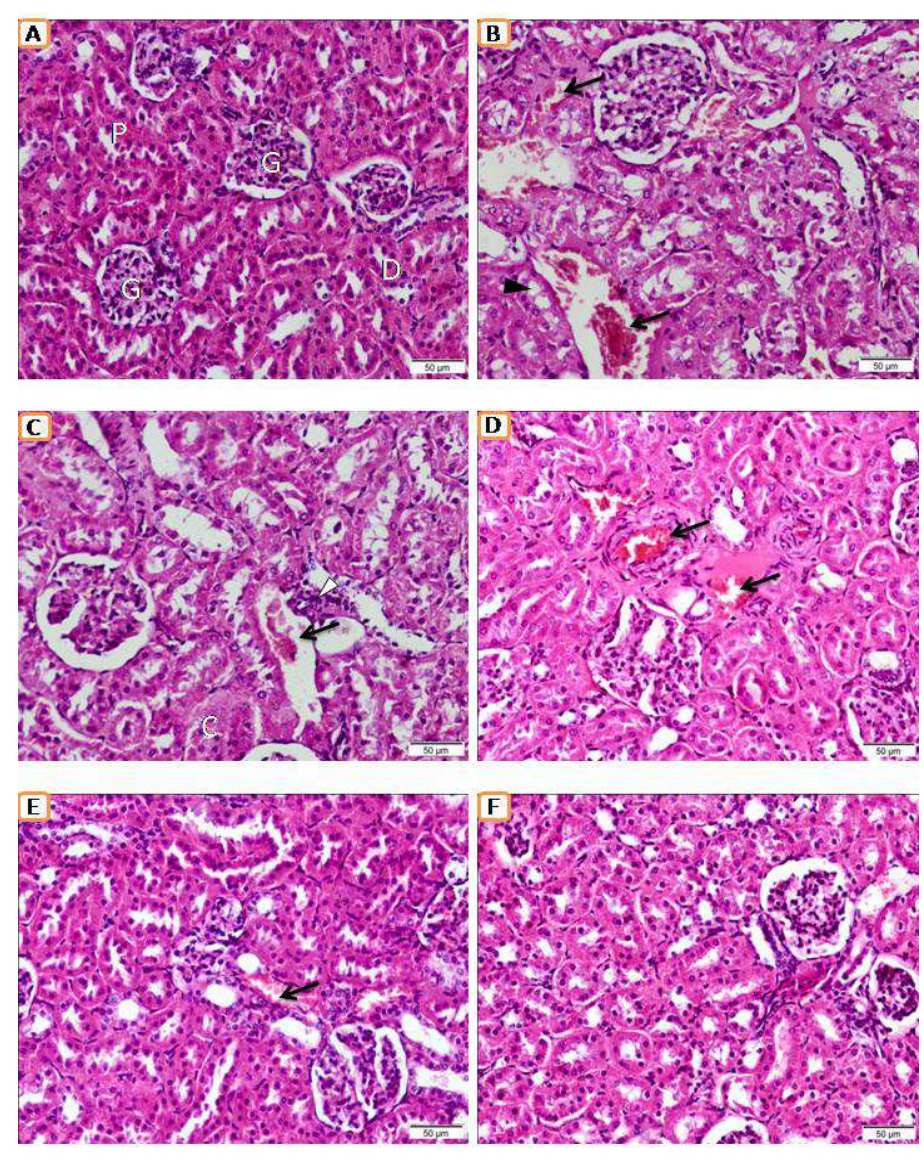

Fig. 2. Photomicrographs of rabbit kdney: A. Control group showing normal renal histological structures of the kidney glomerular (G) and surrounding tubules; proximal (P) and distal tubules (D); B and C. IVM-treated group showing marked vacuolar and hydropic degenerative changes of tubular cells (black arrowheads), areas of mild interstitial infiltration of mononuclear cells (white arrowheads), congestion of the renal blood vessels and intertubular capillaries (arrows), eosinophilic hyaline casts (C) in some renal tubular lumen; D. TTEA group showed mild congestion of the renal blood vessels and intertubular capillaries (arrows), the lining epithelium of the convoluted tubules was mostly appeared degenerated; E. TTE group revealed mild degenerative changes of renal parenchyma with congested blood vessels (arrows); F. Se + vit E group exhibited near normal renal features. H\&E stain

The microscopic examination of sections obtained from the non-treated (negative control) rabbit's liver demonstrated the normal hepatic architecture with normally arranged hepatocytes separated by hepatic sinusoids and radiated from the central vein. The hepatocytes appeared crowded with centrally located spherically basophilic nuclei and acidophilic cytoplasm (Fig. 1A). In contrast, IVM-treated group showed marked degenerative changes among hepatocytes, kuppfer cell hyperplasia, lymphocytic infiltration around the central vein, evidence of marked congestion and dilatation of central vein and sinusoids as well as marked diffuse necrobiotic changes of hepatic tissue. Such degenerative changes were evidenced by vacuolar degeneration in some pyknotic hepatocytes. Moreover, fibrous connective proliferation was observed around the portal area admixed with mononuclear leukocytic infiltration (Fig. 1B-D). TTE treated animals' liver showed degenerative changes, congested and dilated vessels compared to control group, some hepatocytes showed a foamy cytoplasmic picture (Fig. 1E). In the group that was given TTEA along with IVM, the liver sections revealed few degenerative changes of hepatocytes, as well as congestion and dilatation of central vein and sinusouds (Fig. 1F). Meanwhile, Se + vit E treated animals' liver showed near normal hepatic architecture with very mild degenerative changes of some hepatocytes, others showed regeneration in the rest of the cells (Fig. 1G).

The selected kidney sections of control animals showed normal renal glomerular and surrounding tubular histological architecture (Fig. 2A). However, marked degenerative changes of tubular cells, hypercellular glomeruli and areas of mild interstitial infiltration of mononuclear cells were noticed among the renal cortex of IVM-treated animals. Additionally, congestion of the renal blood vessels and intertubular capillaries were also 
observed (Fig. 2B). The degenerative changes of tubular cells are indicated by vacuolar and hydropic degeneration. Additionally, individual epithelial cells were shrunken with pyknotic nuclei. Eosinophilic hyaline casts were seen in some renal tubular lumen (Fig. 2C). Concerning rabbits treated with TTEA, the kidneys showed mild congestion of the renal blood vessels and intertubular capillaries. Additionally, the lining epithelium of the convoluted tubules was mostly appeared degenerated (Fig. 2D). Kidney sections of the TTE treated group revealed mild degenerative changes of renal parenchyma with congested blood vessels (Fig. $2 \mathrm{E})$. The degenerated changes of renal cortex were seen to be disappeared in $\mathrm{Se}+$ vit $\mathrm{E}$ treated group which exhibited near normal renal features (Fig. 2F).

\section{Discussion}

The present work was undertaken to evaluate the comparative hepato-renal protective effects of Tribulus terrestris extracts and Se + vit E after IVM injection in rabbits. Concerning the effects of IVM on the studied hematological parameters, the current results are reliable with those obtained by Ali (1990).

The decreased values of the studied hematological parameters in IVM treated animals can be attributed to the oxidative adverse effect of IVM on the haematopoietic system (Atakisi et al., 2009).

Regarding to the effect of Se plus vit E supplementation, our results partially agree with those reported by (Tras et al., 2000; Mohri et al., 2011) who reported that Se and vit E supplementations had no significant effects on haematological parameters such as RBCs, $\mathrm{Hb}, \mathrm{Ht} \%$, mean corpuscular volume, mean corpuscular haemoglobin concentration and mean corpuscular.

ALT and AST are good sensitive biomarkers directly involved in the extent of hepatic damage and toxicity (El-Demerdash, 2004). The elevation in the level of serum ALT and AST could be attributed to hepatotoxicity resulted from increased hepatocyte cell membranes permeability or even its rupture, leading to leakage of its enzymes into the blood stream (Rabab et al., 2015). In the current study, biochemical analysis indicated moderate elevations in AST, ALT and ALP levels after IVM subcutaneous injection. Such results that denote an adverse effect of IVM on the liver tissue are in agreement with those mentioned by other investigators about the macrocyclic lactones reversible adverse effect on rabbits' (El-Far, 2013; Seddiek et al., 2013) and rats (Arise and Malomo, 2009; Shoeb, 2013; Rabab et al., 2015). The relative reductions in the serum ALT, AST and ALP activities in TTE, TTEA and Se + vit E treated groups suggest a seasonable hepatoprotective effect of these treatments. The damage of the plasma membrane of these tissues at the cellular level, leading to increased efflux of these enzymes into the extracellular fluid.
In the present investigation, administration of IVM to rabbits $(0.2 \mathrm{mg} / \mathrm{month} / \mathrm{kg}$ bw for 2 months $)$ led to insignificant increases in serum urea, creatinine. Similar moderate increases in urea and creatinine levels following IVM injection were reported by other researchers such as Arise and Malomo (2009). These elevations may be due to the direct effect of IVM or their metabolites on the renal tissue. The elevation in creatinine and urea concentrations in IVM treated animals may be attributed to the reduction in glomerular renal filtration or renal tubule dysfunction (Walmsley and White, 1994). IVM was found to significantly decrease the total body's antioxidant capacity and to increase the production of Nitric Oxide (NO) (Atakisi et al., 2009), which in turn can harm the renal tissue, leading to kidney malfunction. Malfunction in the glomerular filtration results in the retention of substances, including urea, uric acid and creatinine and this might be responsible for their high serum levels in the treated groups (Selvakumar et al., 2013).

Adimoelja and Adaikan (1997) observed no significant differences in $\mathrm{Hb}$ levels, in the liver and kidney biomarker enzymes (ALT, AST, Gamma glutamyl transpeptidase, urea and creatinine) before and after TT treatment. In the same direction, Shalan et al. (2007) suggested the hepatoprotective effects of vitamins (C, E), Se and silymarin supplements against alcohol intoxication, these antioxidant supplementations significantly reduced the effect of alcohol intake on serum ALT, AST, ALP and LDH activities. Moreover, Zhao et al. (2013) confirmed the Se plus vit E hepatoprotective effect against arsenic-induced liver injury.

It has been clearly reported that the main causes of ivermectin-induced liver injury is lipid peroxidation induced by increased NO production, which acts as free radical and accelerates oxidative stress (Atakisi et al., 2009). In the presence of oxygen, the free radicals attack polyunsaturated fatty acids of the hepatic and renal cell membranes to produce lipid peroxides leading to hepatic and renal injuries. Scavenging the free radicals by antioxidant substances such as vit E, Se and Tribulus flavanoid and polyphenol compounds can inhibit the chain reaction of lipid peroxidation (Hammoda et al., 2013) and protect parenchymal organs such as liver and kidney. The antioxidant activities of herbal flavanoid and polyphenol compounds are well documented in many research works (Abdou et al., 2015; Harraz et al., 2015). Hence, the hepato-renal protective effects of Tribulus terrestris can be attributed to its high content of antioxidant substances such as total flavanoids and polyphenols compounds (Zheleva-Dimitrova et al., 2012).

Studying the histological sections in kidney of animals administrated with IVM revealed marked degenerative changes of tubular cells are indicated by vacuolar and hydropic degeneration. Additionally, individual epithelial cells were shrunken with pyknotic 
nuclei. Eosinophilic hyaline casts were seen in some renal tubular lumen. The results of the present study agree with the results of Rabab et al. (2015). Animals administrated with IVM and Se plus vit E revealed near normal renal features. Furthermore, the present results agree with the results of Lakshmi et al. (2012) in mice when vitamin $\mathrm{E}$ along with $\mathrm{Cd}$ showed good protective effect. Rabbits administrated with TT extracts showed mild congestion of the renal blood vessels and intertubular capillaries. Additionally, the lining epithelium of the convoluted tubules was mild degenerated.

Studying the histological sections in the liver of animals administrated with IVM revealed marked degenerative changes among hepatocytes. The results of the present study agree with the results of Rabab et al. (2015). Rabbits administrated with IVM in concomitant with Se plus vit E showed near normal hepatic architecture with very mild degenerative changes of some hepatocytes. This result agrees with the results of Lakshmi et al. (2012) in rabbit. This amelioration could be attributed to the antioxygenic role of selenium and vit $\mathrm{E}$ as free radical scavengers and as effective inhibitors of autocatalytic process of lipid peroxidation (Ben Amara et al., 2011). Animals administrated with TT extracts showed few degenerative changes of hepatocytes, as well as congestion and dilatation of central vein and sinusoids. The results of the present study agree with the results of Lakshmi et al. (2012). There findings are probably due to the antioxidant effect of TT extracts (Kadry et al., 2010).

\section{Conclusion}

Administration of Tribulus terrestris extracts with IVM resulted in significant improvement in $\mathrm{RBCs}, \mathrm{Hb}$ and $\mathrm{Ht}$ as compared to IVM alone. Although IVM slightly elevated liver and kidney biomarker enzymes (AST, ALT, ALP, urea and creatinine), concomitant administration of Tribulus terrestris extracts with IVM decreased these elevations and improved hepatic and renal functions. Histologically, Tribulus terrestris ethyl acetate extract markedly improved hepatic architecture, meanwhile Tribulus terrestris ethanol extract revealed substantial renal improvement.

\section{Funding Information}

This research is self-funding; we had no funding grants from any governmental or non-governmental organizations or institutes.

\section{Author's Contributions}

Sally I. Ismaiel: Has collected and analyzed samples, ran all statistical tests and drafted the manuscript.

Sameh M. Farouk: Has collected organ samples, prepared and did all the histopathological examination, conceptualized the research plan and participated in manuscript drafting and revision.

Waleed F. Khalil: Has conceptualized and supervised the research and participated in manuscript drafting and revision.

Raafat A. El-Ramady: Supervised sample collection and analysis and has read and approved the manuscript.

\section{Conflicts of Interest Statement}

All authors declare that there are no conflicts of interest related to this manuscript.

\section{References}

Abdou, R.H., S.Y. Saleh and W.F. Khalil, 2015. Toxicological and biochemical studies on Schinus terebinthifolius concerning its curative and hepatoprotective effects against carbon tetrachlorideinduced liver injury. Pharmacognosy Magazine, 11: 93-101. DOI: 10.4103/0973-1296.157705

Abogresha, N.M., S.M. Greish, E.Z. Abdelaziz and W.F. Khalil, 2016. Remote effect of kidney ischemiareperfusion injury on pancreas: Role of oxidative stress and mitochondrial apoptosis. Archives Med. Sci., 12: 252-262. DOI: 10.5114/aoms.2015.48130

Adimoelja, A. and P.G. Adaikan, 1997. Protodioscin from herbal plant Tribulus terrestris L. improves the male sexual functions, probably via DHEA. Int. J. Impotence Res., 9: 1-15.

DOI: $10.4103 / 0973-7847.112832$

Ali, B.H., 1990. The effect of ivermectin on some haematological indices in rabbits: Influence of vitamin K treatment. Clin. Experim. Pharmacol. Physiol., 17: 735-738. DOI: $10.1111 /$ j.1440-1681.1990.tb01273.x

Al-Othman, A.M., K.S. Al-Numair, G.E. El-Desoky, K. Yusuf and Z.A. Al Othman et al., 2011. Protection oftocopherol and selenium against acute effects of malathion on liver and kidney of rats. Afr. J. Pharmacy Pharmacol., 5: 1263-1271. DOI: 10.5897/AJPP11.226

Arise, R.O. and S.O. Malomo, 2009. Effect of ivermectin and albendazole on some liver and kidney function indices in rats. Afric. J. Biochem. Res., 3: 190-197.

Atakisi, E., O. Atakisi, B. Topcu and M. Uzun, 2009. Effects of therapeutic dose of ivermectin on plasma nitric oxide and total antioxidant capacity in rabbits. Eur. Rev. Med. Pharmacol. Sci., 13: 425-429.

Bancroft, J.D. and M. Gamble, 2008. Theory and Practice of Histological Techniques. 1st Edn., Elsevier Health Sciences, ISBN-10: 0443102791, pp: 725 .

Bauer, J.D., 1970. Numerical Evaluation of Red Blood, White Blood Cells and Platelets, Part III, Hematology. In: Clinical Laboratory Methods and Diagnosis, Frankel, S., S. Reitman and A.C. Somen Wirth, (Eds.), The C.V. Mosby. Co., Saint Louis, USA. 
Ben Amara, A.I., S. Nejla, T. Afef, B. Hanen and B. Tahia et al., 2011. Antioxidant effect of vitamin E and selenium on hepatotoxicity induced by dimethoate in female adult rats. Ecotoxi. Environ. Safety, 201: 811-819.

DOI: $10.1016 /$ j.ecoenv.2010.11.007

Biswas, A., M. Ahmed, V.K. Bharti and S.B. Singh, 2011. Effect of antioxidant on physio-biochemical and hematological parameters in broiler chicken at high altitude. Asian-Aust. J. Anim. Sci., 24: 246-249. DOI: 10.5713 /ajas.2011.10060

Duncan, D.B., 1955. Multiple range and multiple F-tests. Biometrics, 11: 1-42. DOI: 10.2307/3001478

El-Demerdash, F.M., 2004. Antioxidant effect of vitamin $\mathrm{E}$ and selenium on lipid peroxidation, enzyme activities and biochemical parameters in rats exposed to aluminium. J. Trace Elem. Med. Biol., 18: 113-121. DOI: 10.1016/j.jtemb.2004.04.001

El-Far, A.H., 2013. Effect of therapeutic and double therapeutic doses of ivermectin on oxidative status and reproductive hormones in male rabbits. Am. J. Anim. Vet. Sci., 8: 128-133.

DOI: $10.3844 /$ ajavsp.2013.128.133

Ewuola, E.O. and G.N. Egbunike, 2008. Haematological and serum biochemical response of growing rabbit bucks fed dietary fumonisin B1. Afr. J. Biotechnol., 7: 4304-4309.

Gauthaman, K. and P. Adaikan, 2008. The hormonal effect of Tribulus terrestris and its role in the management of male erectile dysfunction-an evaluation using primates, rabbit and rat. J. Phytomedicine, 15: 44-54.

DOI: 10.1016/j.phymed.2007.11.011

Hammoda, H.M., N.M. Ghazy, F.M. Harraz, M.M. Radwan and M.A. ElSohly et al., 2013. Chemical constituents from Tribulus terrestris and screening of their antioxidant activity. Phytochem., 92: 153-159. DOI: 10.1016/j.phytochem.2013.04.005

Harraz, F.M., N.M. Ghazy, H.M. Hammoda, A.A. Nafeaa and I.I. Abdallah, 2015. Hepatoprotective and antioxidant activities of Tribulus terrestris. J. Physiol. Pharmacol. Adv., 5: 787-794.

DOI: $10.5455 /$ jppa.20151111080318

Kadry, H., L. Abou-Basha, O. El Gindi and A. Temraz, 2010. Antioxidant activity of aerial parts of tribulus alatus in rats. Pak. J. Pharm. Sci., 23: 59-62.

Karimi, J.H., S.S. Malekzadeh and F. Hoshmand, 2012. The effect of the Tribulus terrestris extract on spermatogenesis in the rat. J. Jahrom Univ. Med. Sci., 9: 7-11.

Kostova, I. and D. Dinchev, 2005. Saponins in Tribulus terrestris-chemistry and bioactivity. Phytochem. Rev., 4: 111-137. DOI: 10.1007/s11101-005-2833-X

Lakshmi, G.D., P.R. Kumar, K. Bharavi, P. Annapurna and B. Rajendar et al., 2012. Protective effect of Tribulus terrestris Linn on liver and kidney in cadmium intoxicated rats. Ind. J. Exp. Biol., 50: 141-146.
Mohri, M., A. Ehsani, M.A. Norouzian, M.H. Bami and H.A. Seifi, 2011. Parenteral selenium and vitamin E supplementation to lambs: Hematology, serum biochemistry, performance and relationship with other trace elements. Biol. Trace Elem Res., 139: 308-316. DOI: $10.1007 / \mathrm{s} 12011-010-8659-4$

Perkins, S.L., 2009. Examination of the Blood and Bone Marrow. In: Wintrobe's Clinical Hematology, Greer, J.P., J. Foerster, G.M. Rodgers, F. Paraskevas and B. Glader et al. (Eds.), Lippincott Williams and Wilkins, Philadelphia, USA.

Rabab, R.E., A. Amin, A.F. Hamouda and A. Ali, 2015. Toxicological and pathological studies of Ivermectin on male albino rats. J. Am. Sci., 11: 73-83.

Reitman, S. and S.A. Frankel, 1957. Colorimetric method for the determination of serum glutamic oxalacetic and glutamic pyruvic transaminases. Am. J. Clin. Pathol., 28: 56-63. DOI: 10.1093/ajcp/28.1.56

Sangeeta, D., H. Sidhu, S.K. Thind and R. Nath, 1994. Effect of Tribulus terrestris on oxalate metabolism in rats. J. Ethnopharmacol., 44: 61-66. DOI: 10.1016/0378-8741(94)90069-8

Seddiek, S.A., M.M. Ali, H.F. Khater and M.M. ElShorbagy, 2013. The acaricidal efficacy of aqueous neem extract and ivermectin against Sarcoptes scabiei var. cuniculi in experimentally infested rabbits. Parasitol. Res., 112: 2319-2330. DOI: $10.1007 / \mathrm{s} 00436-013-3395-2$

Selvakumar, K., S. Bavithra, S. Suganya, F.A. Bhat and G. Krishnamoorthy, 2013. Effect of quercetin on haematobiochemical and histological changes in the liver of polychlorined biphenyls-induced adult male wistar rats. J. Biomarkers. DOI: $10.1155 / 2013 / 960125$

Shalan, M.G., W.D. Abd Ali and A.G. Shalan, 2007. The protective efficacy of vitamins ( $\mathrm{C}$ and $\mathrm{E}$ ), selenium and silymarin supplements against alcohol toxicity. World Rabbit Sci., 15: 103-110. DOI: 10.4995/wrs.2007.601

Shoeb, Q., 2013. Biochemical toxicity of ivermectin in Wistar Albino rats. Am. Eurasian J. Toxicol. Sci., 5: 15-19. DOI: 10.5829/idosi.aejts.2013.5.1.7374

Stranges, S., A. Navas-Acien, M.P. Rayman and E. Guallar, 2010. Selenium status and cardiometabolic health: State of the evidence. Nutr. Metab. Cardiovasc. Dis., 20: 754-760. DOI: 10.1016/j.numecd.2010.10.001

Suarez, G., L. Alvarez, D. Castells, O. Correa and P. Fagiolino et al., 2013. Relative bioavailability and comparative clinical efficacy of different ivermectin oral formulations in lambs. BMC Vet. Res., 9: 27-27. DOI: $10.1186 / 1746-6148-9-27$

Tras, B., F. Inal, A.L. Bas, V. Altunok and M. Elmas et al., 2000. Effect of continuous supplementations of ascorbic acid, aspirin, vitamin $\mathrm{E}$ and selenium on some haematological parameters and serum superoxidase dismutase levels in broiler chickens. British Poul. Sci., 41: 664-666. DOI: $10.1080 / 00071660020009225$ 
Van Kampen, E.J. and W.G. Zillstra, 1983. Spectrophotometry of hemoglobin and hemoglobin derivatives. Adv. Clin. Chem., 23: 199-257. DOI: $10.1016 / \mathrm{S} 0065-2423(08) 60401-1$

Walmsley, R.N. and G.H. White, 1994. A Guide to Diagnostic Clinical Chemistry. 3rd Edn., Blackwell Scientific Publications, Oxford, ISBN-10: 0632037350, pp: 637.

Yatzidis, H., M. Garidi, C. Vassilikos, D. Mayopoulou and A. Akilas, 1964. An improved method for the simple and accurate colorimetric determination of urea with Ehrlich's reagent. J. Clin. Pathol., 17: 163-164. DOI: 10.1136/jcp.17.2.163

Young, D.S., L.C. Pestaner and V. Gibberman, 1975. Effects of drugs on clinical laboratory tests. Clin. Chem., 21: 431-432. PMID: 1091375
Yuan, X. and C. Tang, 1999. Lead effect on DNA and albumin chicken blood and the protection of selenium nutrition. J. Environ. Sci. Health A., 34: 1875-1887. DOI: 10.1080/10934529909376935

Zhao, X., W. Zhou, L. Jian-Jun, C. Chen and PingChuan et al., 2013. Protective effects of selenium on oxidative damage and oxidative stress related gene expression in rat liver under chronic poisoning of arsenic. Food Chem. Toxicol., 58: 1-7. DOI: $10.1016 /$ j.fct.2013.03.048

Zheleva-Dimitrova, D., D. Obreshkova and P. Nedialkov, 2012. Antioxidant activity of Tribulus terrestris - a natural product in infertility therapy. Int. J. Pharmacy Pharmaceutical Sci., 4: 508-511. 